\title{
Computer-Assisted Cognitive Rehabilitation in Stroke and Alzheimer's disease
}

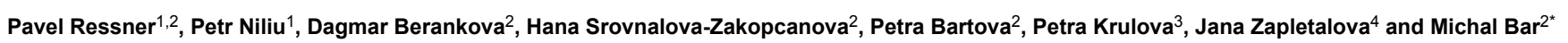

1 University Hospital Ostrava, Department of Neurology, Ostrava, Czech Republic

2University of Ostrava, Faculty of Medicine, Department of Clinical Studies, Ostrava, Czech Republic

${ }^{3}$ University of Ostrava, Faculty of Medicine, Department of Nursing and Midwifery, Ostrava, Czech Republic

${ }^{4}$ Palacky University Olomouc, Faculty of Medicine and Dentistry Department of Medical Biophysics, Institute of Molecular and Translational Medicine, Czech Republic

*Corresponding author: Bar Michal, University of Ostrava, Faculty of Medicine, Department of Clinical Studies, 17 Listopadu 1790 , Ostrava 70852 , Czech Republic, Tel: 00420605531979; E-mail: michal.bar@fno.cz

Received date: Oct 23, 2014, Accepted date: Dec 10, 2014, Published date: Dec 15, 2014

Copyright: ( 2014 Ressner P, et al. This is an open-access article distributed under the terms of the Creative Commons Attribution License, which permits unrestricted use, distribution, and reproduction in any medium, provided the original author and source are credited.

\section{Abstract}

Background: The aim of study was to compare the effects of computer-assisted cognitive rehabilitation (CR) in mild cognitive impairment after stroke and in patients with Alzheimer disease.

Methods: The study included 21 patients after ischemic stroke (12 males, 9 females, age median 60.5 age range 38-81 years) and 15 patients with AD (8 males and 7 females 71.5,50-86 years). We administered WAIS-III, MMSE, and ACE-R to evaluate $\mathrm{MCl}$. NEUROP-4 software was employed for CR. Rehabilitation was carried out for two periods of $1.5 \mathrm{~h}$ each week for 3 months.

Results: In the stroke group we recorded significantly higher scores for the following parameters after CR: IQc (median 84 before vs 88 after $p=0,001)$, IQv (83 vs 92, $p=0.029$ ), IQp ( 78 vs 86, $p=0.001$ ), VC (91 vs 97, $p=$ $0,017$ ), PO (82 vs $94, p=0.001)$, SOP (71 vs $8, p=0.0003)$, ACE-R (79 vs $84, p=0.01)$ In the AD group only the ACE-R was increased ( 75 vs $83, p=0.008)$.

Conclusions: Our study demonstrates that the beneficial effects of computer-assisted $\mathrm{CR}$ in patients with $\mathrm{MCl}$ are more significant in stroke patients than in $A D$ patients.

Keywords: Cognitive rehabilitation; Alzheimer disease; Stroke; Cognitive impairment

\section{Abbreviations:}

AD: Alzheimer disease; ACE-R: Addenbrooke's Cognitive Examination, revised; CR: Cognitive rehabilitation; HADS: Hospital Anxiety and Depression Scale; IQc: IQ score global; IQp: IQ score performance; IQv: IQ score verbal; MMSE: Mini-Mental State Examination; WM: Working memory; PO: Perceptual organization; SOP: Speed of processing; VC: Verbal comprehension; WAIS-III Wechsler Adult Intelligence Scale, third revision

\section{Background}

Cognitive functions are impaired in brain disorders including neurodegenerative diseases, stroke, and brain trauma. Treatment is typically pharmacological $[1,2]$ and, in some cases, neurosurgical. However, non-pharmacological intervention, especially cognitive rehabilitation, was often neglected in the past but now there have been increasing efforts to develop cognitive interventions to ameliorate cognitive problems experienced by older adults, especially $\mathrm{AD}$, stroke and brain trauma patients $[3,4]$.

Computer- based programs specifically targeted to dementia or mild cognitive impairment have been developed as a support in rehabilitation of cognitive areas and daily living functions [5]. Computer-assisted CR is a cost-effective method for providing individualized treatment, based on each patient's neuropsychological patterns, in which impaired cognitive areas are repeatedly stimulated [6]. Computer interventions are rapidly becoming popular and cognitive exercise has been successfully implemented because older adults are often the fastest growing group of computer technology users [7].

CR provides a structured practice of complex mental activity designed to enhance cognitive function $[3,8]$. Neural plasticity is a prerequisite for improvement of cognitive impairment following CR $[9,10]$. Several studies have been carried out on the effect of cognitive training and rehabilitation in different diseases associated with cognitive impairment. Most studies have reported mild beneficial effects of $\mathrm{CR}$ in patients with neurodegenerative disease such as $\mathrm{AD}$ [5,9,11-13]. However, studies on CR in stroke patients have been more promising [10,14-17]. Data comparing the effects of CR in patients with acute brain lesions versus chronic progressive disease, notably neurodegenerative conditions such as $\mathrm{AD}$, are needed.

The aim of this pilot study was therefore to compare the effects of computer-assisted $\mathrm{CR}$ in patients with mild cognitive impairment following stroke versus patients with mild cognitive impairment attributed to probable $\mathrm{AD}$.

\section{Methods}

Cognitive rehabilitation: For computer-assisted rehabilitation we used the software NEUROP-4. This program provides multimodal and 
multiple-domain training of cognitive function. In order to brain memory and concentration function, we used non-verbal tasks such as assembling shapes or figures, getting through a labyrinth, memorizing cards and shapes. We used tasks focused on planning and strategic thinking for executive functions training, e.g. London Tower, Hanoi Tower, etc.

Rehabilitation was carried out for two periods of $1.5 \mathrm{~h}$ each week for 3 months. Rehabilitation was supervised by a neuropsychologist. The battery of the cognitive tests was administered both before the start of computer-assisted CR and after completion of CR. The effect of CR was assessed as the difference between baseline scores and posttraining scores within the each group, and also by comparison between the two groups.

Data analysis: All results are expressed as median and minimummaximum values. SPSS v.15 (SPSS Inc., Chicago, USA) statistical software was used to analyze the data. The Wilcoxon signed-rank test was applied to compare the paired data, and the Mann-Whitney U test was used to compare the groups. Spearman's correlation analysis was carried out to evaluate the relationship between age, other baseline variables and differences in cognitive scores in both groups. Analysis of covariance ANCOVA was used for analysis of differences between the groups with age as a covariate. Nonparametric tests were used owing to small sample sizes. $\mathrm{P}<0.05$ was taken to indicate statistical significance.

\section{Results}

We included 21 patients in our prospective study after ischemic stroke (12 males, 9 females, age median 60.5, age range 38-81 years) and 15 patients with probable $\mathrm{AD}(8$ males and 7 females, age median 71.5 , age range $50-86$ years). Patients in both groups were matched with respect for age and sex. Table 1 presents the results of the cognitive tests before beginning the treatment in both groups. Table 2 compares the scores on the cognitive test battery at baseline and following $\mathrm{CR}$, as presents the changes in scores following $\mathrm{CR}$.

\begin{tabular}{|l|l|l|l|}
\hline & AD $(\mathbf{n}=\mathbf{1 5})$ & Stroke $(\mathbf{n}=\mathbf{2 1})$ & $\mathbf{p}$ \\
\hline Sex & & & \\
\hline M/F & $7 / 8$ & $15 / 6$. & $0.175 \mathrm{a}$ \\
\hline Age,y & $71.5(50-86)$ & $60.5(38-81)$ & $0.020 \mathrm{~b}^{*}$ \\
\hline ACE-R & $79.0(54-97)$ & $74.5(28-94)$ & $0.385 \mathrm{~b}$ \\
\hline MMSE & $27.0(24-30)$ & $26.0(10-30)$ & $0.409 \mathrm{~b}$ \\
\hline HADS & $14.5(12-26)$ & $14.0(2-30)$ & $0.459 \mathrm{~b}$ \\
\hline Education,y & $12(5-21)$ & $13(6-24)$ & $0.321 \mathrm{~b}$ \\
\hline
\end{tabular}

Table 1: Baseline characteristics of the study population; a ... Fisher's exact test, $\mathrm{b}$... Mann-Whitney $\mathrm{U}$ test Data in the table are presented as median (minimum - maximum). ${ }^{\star}$ Spearman correlation did not prove significant relationship between age and other baseline variables in both groups.

In the stroke group, the Wilcoxon signed-rank test demonstrated statistically significant increased scores after the therapy for the majority of parameters, including WAIS-III, ACE-R, and MMSE. IQc (median 84 before vs 88 after, $\mathrm{p}=0.001$ ), IQv (median 83 vs $92, \mathrm{p}=$ 0.029), IQp (median 78 vs $86, \mathrm{p}=0.001$ ), VC (median 91 vs $97, \mathrm{p}=$
0.017), PO (median 82 vs 94, $\mathrm{p}=0.001$ ), SOP (median 71 vs $8, \mathrm{p}=$ 0.0003 ), ACE-R (median 79 vs $84, \mathrm{p}=0.01$ ) Only one parameter, VM, did not change significantly in the stroke group (median 84 vs $85, \mathrm{p}=$ 0.833 ).

\begin{tabular}{|l|l|l|l|l|l|l|}
\hline $\begin{array}{l}\text { Cognitive } \\
\text { domains }\end{array}$ & \multicolumn{4}{|l|}{ AD (n=15) } & \multicolumn{4}{l|}{ Stroke (n=21) } \\
\hline & Before & After & $\mathbf{p}$ & Before & After & $\mathbf{p}$ \\
\hline IQC & $\begin{array}{l}87 \\
(74-110)\end{array}$ & $92(66-112)$ & 0,61 & $\begin{array}{l}84 \\
(64-112)\end{array}$ & $\begin{array}{l}88 \\
(71-121)\end{array}$ & 0,001 \\
\hline IQV & $\begin{array}{l}95 \\
(61-119)\end{array}$ & $98(60-119)$ & 0,755 & $\begin{array}{l}83 \\
(67-127)\end{array}$ & $\begin{array}{l}93 \\
(69-126)\end{array}$ & 0,029 \\
\hline IQp & $\begin{array}{l}81 \\
(68-105)\end{array}$ & $85(57-114)$ & 0,208 & $78(61-99)$ & $\begin{array}{l}86 \\
(68-111)\end{array}$ & 0,001 \\
\hline VC & $\begin{array}{l}93 \\
(34-126)\end{array}$ & $\begin{array}{l}102 \\
(64-126)\end{array}$ & 0,835 & $\begin{array}{l}91 \\
(68-129)\end{array}$ & $\begin{array}{l}97 \\
(66-129)\end{array}$ & 0,017 \\
\hline PO & $\begin{array}{l}84 \\
(30-109)\end{array}$ & $90(60-107)$ & 0,889 & $\begin{array}{l}82 \\
(72-101)\end{array}$ & $\begin{array}{l}94 \\
(62-121)\end{array}$ & 0,001 \\
\hline WM & $\begin{array}{l}90 \\
(32-113)\end{array}$ & $94(70-110)$ & 0,561 & $\begin{array}{l}84 \\
(67-117)\end{array}$ & $\begin{array}{l}85 \\
(65-115)\end{array}$ & 0,833 \\
\hline SOP & $81(7-113$ & $86(6-117)$ & 0,382 & $\begin{array}{l}71 \\
(11-120)\end{array}$ & $\begin{array}{l}81 \\
(63-118)\end{array}$ & 0,0003 \\
\hline ACER & $79(54-97)$ & $84(58-98)$ & 0,01 & $75(28-94)$ & $83(49-95)$ & 0,008 \\
\hline MMSE & $27(24-30)$ & $29(24-30)$ & 0,094 & $26(10-30)$ & $28(20-30)$ & 0,395 \\
\hline
\end{tabular}

Table 2: Scores on the cognitive test battery at baseline and after cognitive rehabilitation; $\mathrm{p}$... significance of Wilcoxon signed-rank test for comparing before and after therapy, score median (min-max)

\begin{tabular}{|c|c|c|c|}
\hline Cognitive domains & AD & Stroke & \multirow{2}{*}{$\mathbf{p}$} \\
\hline & $\mathbf{( n = 1 5 )}$ & $\mathbf{( n = 2 1 )}$ & 0,001 \\
\hline IQC & $-1,5(-15 \ldots 10)$ & $7,0(-3 \ldots 16)$ & 0,08 \\
\hline IQV & $-0,5(-17 \ldots 10)$ & $3,0(-56 \ldots 25)$ & 0,001 \\
\hline IQp & $-4,5(-14 \ldots 9)$ & $6,0(-4 \ldots 20)$ & 0,089 \\
\hline VP & $0(-12 \ldots 75)$ & $4,0(-6 \ldots 31)$ & 0,017 \\
\hline PO & $1,0(-14 \ldots 77)$ & $8,0(0 \ldots 28)$ & 0,66 \\
\hline WM & $1,0(-24 \ldots 77)$ & $0(-12 \ldots 10)$ & 0,049 \\
\hline SOP & $2,0(-26 \ldots 92)$ & $10,0(-2 \ldots 87)$ & 0,904 \\
\hline ACER & $4,0(-7 \ldots 16)$ & $3,0(-11 \ldots 15)$ & 0,6 \\
\hline MMSE & $1,0(-2 \ldots 5)$ & $0(-4 \ldots 5)$ & 0,46 \\
\hline HADS & $0(-10 \ldots 12)$ & $-2,0(-9 \ldots 17)$ & \\
\hline
\end{tabular}

Table 3: Differences in cognitive scores between the stroke group and AD group; Significance of Mann-Whitney $U$ test for comparison of $\mathrm{AD}$ and stroke group median of difference before and after the therapy (maximum decline and maximum elevation)

By contrast, only ACE-R scores were significantly increased following rehabilitation in the AD group (median 75 vs $83, p=0.008$ ); 
no significant improvements were recorded in any of the other tests applied.

Table 3 presents the differences in cognitive scores between the stroke group and the $\mathrm{AD}$ group. The Mann-Whitney $\mathrm{U}$ test demonstrated a statistically significant difference between the stroke and $\mathrm{AD}$ groups in changes in the parameters IQc $(\mathrm{p}=0.001), \mathrm{IQv}(\mathrm{p}=$ $0.001)$, PO ( $\mathrm{p}=0.017)$, and SOP $(\mathrm{p}=0.049)$.

Table 4 shows ANCOVA analysis of differences between the groups with age as a covariate. ANCOVA proves the significant difference between the groups only in one outcome parameter IQp $(p=0,015)$.

\begin{tabular}{|c|c|c|c|}
\hline $\begin{array}{l}\text { Adjusted mean difference } \\
\text { before-after }\end{array}$ & \multirow[t]{2}{*}{$\begin{array}{l}A D \\
(n=15)\end{array}$} & $\begin{array}{l}\text { Stroke } \\
(n=21)\end{array}$ & \multirow[b]{2}{*}{$p$} \\
\hline & & & \\
\hline IQc & 0,002 & 5,311 & 0,052 \\
\hline IQv & 1,39 & 2,221 & 0,747 \\
\hline IQp & $-1,294$ & 6,757 & 0,015 \\
\hline VP & 5,359 & 3,665 & 0,803 \\
\hline PO & 5,688 & 9,091 & 0,636 \\
\hline PP & 5,75 & $-1,5$ & 0,316 \\
\hline RZ & 9,242 & 10,04 & 0,925 \\
\hline ACER & 4,242 & 3,974 & 0,909 \\
\hline MMSE & 0,889 & 0,504 & 0,678 \\
\hline HADS & $-0,046$ & 0,601 & 0,904 \\
\hline
\end{tabular}

Table 4: ANCOVA analysis of differences between the groups with age as a covariate.

Spearman's correlation analysis showed the significant relationship between age and differences in some cognitive scores only in the stroke group ( IQc $\rho=0.601$; IQv $\rho=0.565$, PO $\rho=0,535$ ). In the AD group, Spearman's correlation analysis does not prove any relationship between age and any outcome variables.

We conclude that cognitive parameters were significantly improved by $\mathrm{CR}$ in the stroke group, whereas there was little significant change in the $\mathrm{AD}$ group.

\section{Discussion}

This study demonstrates that the beneficial effects of computerassisted CR in patients with mild cognitive impairment are much more significant in stroke patients than in patients with similar mild cognitive impairment attributable to probable Alzheimer disease.

This result is supported by other studies. Systemic review and metaanalysis by Cha and Kim [16] indicated that the overall effect size of computer-assisted CR in patients with stroke is 0.54 (95\% CI; $0.33-$ 0.74 ). That can be interpreted as a medium effect size. By contrast, the beneficial effects of $\mathrm{CR}$ in $\mathrm{AD}$ patients are at best 'mild', [5,13] although no direct comparison between these groups has yet been performed [18]. In addition, previous studies found no significantly different effects of CR in the patients in the acute versus chronic stroke phases [14]. In our study we therefore enrolled stroke patients from a single period (3 months after stroke).

Our results confirm the hypothesis that computer-assisted CR is more effective in patients with acute structural brain lesions (stroke) than in neurodegenerative diffuse brain disease (AD). Because brain plasticity is probably crucial for successful CR, one might anticipate a greater effect of CR in patients with acute demarcated brain lesions (as in stroke) than in patients with a diffuse neurodegenerative disorder.

We also report some improvement of cognitive function in the $\mathrm{AD}$ group, but the improvement was only seen in one test (ACE-R) and the extent of improvement was limited. Generally, the beneficial effects of CR were not observed using MMSE; we surmise that MMSE is unsuitable for screening patients before CR, and ACE-R is likely to be a more appropriate screening test in this context.

Study limitations: First, heterogeneity, in our study we included patients after stroke whose lesions were located variably (11 patients with lesions in the left hemisphere, 7 patients with lesions in the both hemispheres, and 3 with lesions in the right hemisphere).

Second, owing to the small number of patients in our study it was not possible to analyze cognitive subgroups such as memory, thinking operations, executive functions, and orientation. Third, there was a significant difference in age between the groups, but we excluded the relationship between age and other baseline variables in both groups.

ANCOVA, age as a covariate, showed the significant difference between the groups only in one outcome variable (IQ score global).

Despite the limitations of our study, statistical analysis provides preliminary evidence for the differential effects of CR in patients with mild cognitive impairment following stroke versus similar impairment attributed to probable $\mathrm{AD}$. The effectiveness of $\mathrm{CR}$ in $\mathrm{AD}$ is unsatisfactory and there is a question of future aiming of the computer-assisted $\mathrm{CR}$ in $\mathrm{AD}$ patients. There is also no clear long-time effect of CR after stroke, and therefore we plan to retest our patients after one year.

\section{Conclusion}

We report that computer-assisted CR is likely to provide greater cognitive benefits in patients with mild cognitive impairment after stroke than in patients with similar impairment attributable to AD. For screening of patients before CR, ACE-R testing may be superior to MMSE. Further studies are necessary to evaluate the generalizability of our results.

\section{References}

1. Tifratene K, Sakarovitch C, Rouis A, Pradier C, Robert P (2014) Mild cognitive impairment and anti-Alzheimer disease medications: A cross sectional study of the French National Alzheimer Databank (BNA). J Alzheimers Dis 38: 541-549.

2. Grandy JK (2013) Melatonin: Therapeutic Intervention in Mild Cognitive Impairment and Alzheimer Disease. J Neurol Neurophysiol 4: 148.

3. Martin M, Clare L, Altgassen AM, Cameron MH, Zehnder F (2011) Cognition-based interventions for healthy older people and people with mild cognitive impairment. Cochrane Database Syst Rev : CD006220.

4. Acevedo A, Loewenstein DA (2007) Nonpharmacological cognitive interventions in aging and dementia. J Geriatr Psychiatry Neurol 20: 239-249.

5. Cipriani G, Bianchetti A, Trabucchi M (2006) Outcomes of a computerbased cognitive rehabilitation program on Alzheimer's disease patients 
Citation: $\quad$ Ressner P, Nilius P, Berankova D, Srovnalova-Zakopcanova H, Bartova P, et al. (2014) Computer-Assisted Cognitive Rehabilitation in Stroke and Alzheimer's disease. J Neurol Neurophysiol 5: 260. doi:10.4172/2155-9562.1000260

Page 4 of 4

compared with those on patients affected by mild cognitive impairment Arch Gerontol Geriatr 43: 327-335.

6. Stringer AY (2003) Cognitive rehabilitation practice patterns: a survey of American Hospital Association Rehabilitation Programs. Clinical Neuropsychologist 17: 34-44.

7. Wagner N, Hassanein K, Head M (2012) Computer use by older adults: A multi-disciplinary review. Computers in Human Behavior 26: 870-882.

8. Clare L, Woods RT, Moniz Cook ED, Orrell M, SpectorA (2013) Cognitive rehabilitation and cognitive training for early stage. Alzheimer's disease and vascular dementia. Cochrane Database Syst Rev 6: CD003260.

9. Belleville S, Clément F, Mellah S, Gilbert B, Fontaine F, et al. (2011) Training-related brain plasticity in subjects at risk of developing Alzheimer's disease. Brain 134: 1623-1634.

10. Cumming TB, Marshall RS, Lazar RM (2013) Stroke, cognitive deficits, and rehabilitation: still an incomplete picture. Int J Stroke 8: 38-45.

11. Ballard C, Khan Z, Clack H, Corbett A (2011) Nonpharmacological treatment of Alzheimer disease. Can J Psychiatry 56: 589-595.

12. Luttenberger K, Hofner B, Graessel E (2012) Are the effects of a nondrug multimodal activation therapy of dementia sustainable? Follow-up study 10 months after completion of a randomised controlled trial. BMC Neurol 12: 151.

13. Werheid K, Thöne-Otto AI (2006) [Cognitive training in Alzheimer's dementia]. Nervenarzt 77: 549-557.

14. Lincoln NB (2011) Cognitive rehabilitation for memory deficits following stroke. Cochrane Database Syst. Rev 3. CD002293.

15. Geusgens CA, van Heugten CM, Cooijmans JP, Jolles J, van den Heuvel WJ (2007) Transfer effects of a cognitive strategy training for stroke patients with apraxia. J Clin Exp Neuropsychol 29: 831-841.

16. Cha YJ, Kim H (2013) Effect of computer-based cognitive rehabilitation (CBCR) for people with stroke: a systematic review and meta-analysis. NeuroRehabilitation 32: 359-368.

17. Nordvik JE, Schanke AK, Walhovd K, Fjell A, Grydeland H, et al. (2012) Exploring the relationship between white matter microstructures and working memory functioning following stroke: a single case study of computerized cognitive training. Neurocase 18: 139-151.

18. Gates N, Fiatarone Singh MA, Sachdev PS, Valenzuela M (2013) The effect of exercise training on cognitive function in older adults with mild cognitive impairment: a meta-analysis of randomized controlled trials. Am J Geriatr Psychiatry 21: 1086-1097. 